\title{
Water Resources Management Collection of condensate water: Global potential and water quality impacts --Manuscript Draft--
}

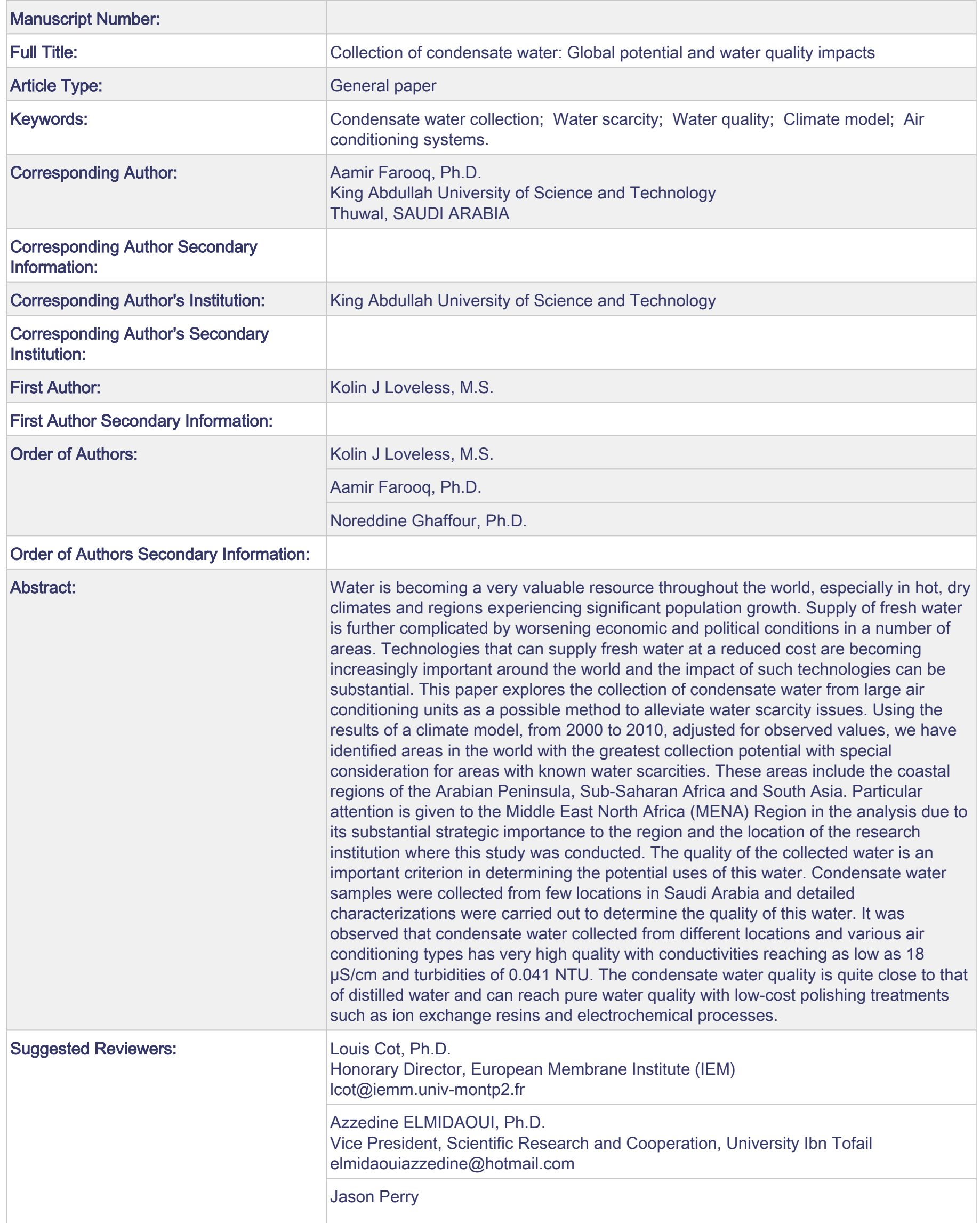


Research Engineer, University of Georgia jperry@engr.uga.edu

Powered by Editorial Manager ${ }^{\circledR}$ and Preprint Manager ${ }^{\circledR}$ from Aries Systems Corporation 


\title{
Collection of condensate water: Global potential and water quality impacts
}

\author{
Kolin J. Loveless ${ }^{\mathrm{a}}$, Aamir Farooq ${ }^{\mathrm{a}^{*}}$, Noreddine Ghaffour ${ }^{\mathrm{b}}$ \\ ${ }^{a}$ Clean Combustion Research Center, Division of Physical Sciences and Engineering, King Abdullah University of Science and \\ Technology (KAUST), Thuwal 23955-6900, Saudi Arabia \\ ${ }^{b}$ Water Desalination \& Reuse Centre, King Abdullah University of Science and Technology (KAUST), Thuwal 23955-6900, Saudi Arabia \\ *Corresponding Author, Email: aamir.farooq@kaust.edu.sa, Tel: +966-28082704.
}

\begin{abstract}
Water is becoming a very valuable resource throughout the world, especially in hot, dry climates and regions experiencing significant population growth. Supply of fresh water is further complicated by worsening economic and political conditions in a number of areas. Technologies that can supply fresh water at a reduced cost are becoming increasingly important around the world and the impact of such technologies can be substantial. This paper explores the collection of condensate water from large air conditioning units as a possible method to alleviate water scarcity issues. Using the results of a climate model, from 2000 to 2010, adjusted for observed values, we have identified areas in the world with the greatest collection potential with special consideration for areas with known water scarcities. These areas include the coastal regions of the Arabian Peninsula, Sub-Saharan Africa and South Asia. Particular attention is given to the Middle East North Africa (MENA) Region in the analysis due to its substantial strategic importance to the region and the location of the research institution where this study was conducted. The quality of the collected water is an important criterion in determining the potential uses of this water. Condensate water samples were collected from few locations in Saudi Arabia and detailed characterizations were carried out to determine the quality of this water. It was observed that condensate water collected from different locations and various air conditioning types has very high quality with conductivities reaching as low as $18 \mu \mathrm{S} / \mathrm{cm}$ and turbidities of $0.041 \mathrm{NTU}$. The condensate water quality is quite close to that of distilled water and can reach pure water quality with low-cost polishing treatments such as ion exchange resins and electrochemical processes.
\end{abstract}

Keywords: Condensate water collection; Water scarcity; Water quality; Climate model; Air conditioning systems. 


\section{Introduction}

As water supply becomes an increasingly complex and global problem, technologies that can collect water from the air around us have received attention as possible solutions (Chartrand, 2001). One variation of such solutions is condensate recovery from air conditioning systems and recently became a requirement for all new commercial buildings in the city of San Antonio, Texas (Guz, 2005). The University of Texas at Austin and Bahrain Airport Services also boast large-scale collection systems and use the resulting water for irrigation, toilettes, and washing with considerable savings (Guz, 2005). While these methods show some promise for certain regions of the world, they are highly dependent on a warm and humid climate like in the southern regions of Texas and Florida. Guz (2005) and Lawrence et al. (2010) note that collection is possible even in some northern US cities in the summer months under the right conditions. The humidity ratio, or specific humidity, of ambient air governs the volume of water that can be collected and closely predicts the volume of water collected as shown by Lawrence et al. (2010). Another study notes that laboratory buildings are often prime candidates for condensate recovery because they often require large airflow rates from outside ambient conditions through the building's air handling units (AHUs). In a case study of a laboratory building in San Antonio, Painter (2009) found that condensate collection could provide for the building's total urinal and water closet needs as well as part of the building's cooling tower water demand.

According to the World Health Organization (WHO), more than one out of six people lack access to safe drinking water (WHO, 2008). Polluted water is estimated to affect the health of more than 1.2 billion people, and contributes to the death of an average 15 million children every year. Critical water shortages and drought in Waste Asia and North Africa as a whole affect the region's social and economic potential, increase land vulnerability to salinization and desertification, and raise the risk of political conflict around this limited resource (Brooks and Mehmet, 2000; Jagerskog, 2003; Tropp and Jagerskog, 2006; El Kharraz et al., 2012). West Asia and North Africa form the driest region in the world with renewable water resources less than the critical level of $1,000 \mathrm{~m}^{3}$ per inhabitant per year, as defined by WHO. According to Allan (2002), the region "ran out of water in the 70s" and is currently surviving on virtual water and in some cases it is over-exploiting its own renewable water resources. Population growth rate in this region is high with an average of about 2.5\% (Quteishat, 2009). Industrial growth is also high due to the availability of relatively cheap energy resources in oil-rich countries of the Arabian Gulf, amongst other factors. Therefore, in most of these countries, withdrawal of available water resources is much above the rechargeable level. Alternative sources like desalination are thus used to partially meet the growing demand for water (Drouiche et al., 2011). However, desalination is energy intensive and its cost is still high despite the spectacular technology improvements (Reddy and 
Ghaffour, 2007). Collection of high-quality, low-cost clean water from the huge number of airconditioning systems installed in regions where potable water is not available could be a great solution to increase total water supply.

There is a strong potential for condensate collection technology to impact water shortages in the regions of the world where suitable conditions exist. While the southeast United States is the most ideal climate in that country and houses many of the existing collection systems, there are many places in the world with even more favorable climates. Further, potable water is relatively plentiful in southeast of United States compared to many developing nations, which are known to have vast water scarcity issues and can benefit significantly from condensate collection technology. Global climate models can be used to identify regions in the world with optimum conditions for condensate collection. Here, we use a climate model to highlight regions of the world having a high condensate collection potential with special consideration for regions with known water scarcities. These areas include the coastal regions of the Arabian Peninsula, Sub-Saharan Africa and South Asia.

In many cases condensate water is discharged into sewer systems. However, condensate water can be used for a number of applications without treatment, thereby displacing consumption of potable water. In this work, water quality tests were performed for condensate water samples collected from different locations in Saudi Arabia with different climate conditions in order to improve understanding of quality of condensate water and its potential uses. Results indicated that condensate water collected from both humid and dry air zones was of very high quality, having total dissolved solids (TDS) as low as $15 \mathrm{mg} / \mathrm{L}$. By comparison, potable water produced by multi-stage flash and reverse osmosis seawater desalination processes have a TDS of about 50 and $300 \mathrm{mg} / \mathrm{L}$, respectively, after post-treatment process (Gacem et al., 2012). Condensate water of this quality can be used in a number of valuable applications including municipality, irrigation, specific industries such as electronics and boilers, and various medical functions.

\section{Global climate model}

The volume of collectible condensate water is largely dependent on specific humidity, which in turn is dependent on weather patterns. This makes detailed predictions somewhat difficult. However, climate conditions averaged over a long period of time can be used to make design predictions. In a previous work, Lawrence and Perry (2010) used the TMY3 climate dataset (Wilcox and Marion, 2007) to predict collection potential for a given year in the United States. While TMY3 dataset contains data for the United States including Guam, Puerto Rico, and the US Virgin Island, there are climate databases that record conditions globally and can be used to predict collection potential with reasonable accuracy for 
any location in the world. One such database has been created by the European Center for Midterm Climate Weather Forecasts (ECMWF), which is regarded as the most accurate medium-range global weather forecasting system. In order to study past changes in climate, the Reanalysis project (Dee et al., 2011) used the ECMWF model along with observed conditions (dating back to 1957) at a number of global locations and altitudes to create a series of databases that reflect weather conditions on a global grid. The databases contain a number of variables of interest to climatology. For the work presented in this paper, specific humidity data nearest to the earth's surface was extracted from the latest Reanalysis data, ERA-INT, which represents data from 1979 to 2011 (Dee et al., 2011). The ERA-INT data set contains data on a $1.5^{\circ}$ latitude by $1.5^{\circ}$ longitude global grid, and the data is given at 6 -hour time intervals starting at 0000 UTC (Coordinated Universal Time). Here, we applied the same calculation made by Lawrence et al. (2010) to ERA-INT specific humidity data from January 1, 2000 to December 31,2010 in order to give reasonably accurate design predictions for future condensate collection systems on a global scale. Using this data, we analyzed specific humidity behavior over the eleven-year period in order to understand the humidity trends across the globe.

\section{Daily humidity cycle}

Condensate water can only be collected from air conditioning systems when the specific humidity of intake air is greater than that of the conditioned space. Since temperature and specific humidity vary throughout the day, some locations are only able to collect condensate during a few hours of the day while others may be able collect 24 hours a day depending on the conditions. Figure 1 shows specific humidity data extracted from the ERA-INT model for six highly populated cities. The data are plotted on the 2010 fall equinox, which occurred on September 23rd. Assuming a standard design condition of $0.0078 \mathrm{lb}$ water/lb air (kg water/kg air) specific humidity in conditioned space, we can see that Jeddah, Calcutta, Manila, and Caracas would have been able to collect condensate throughout the day, while Houston and Kinshasa would have only been able to collect during a few hours of the day. 


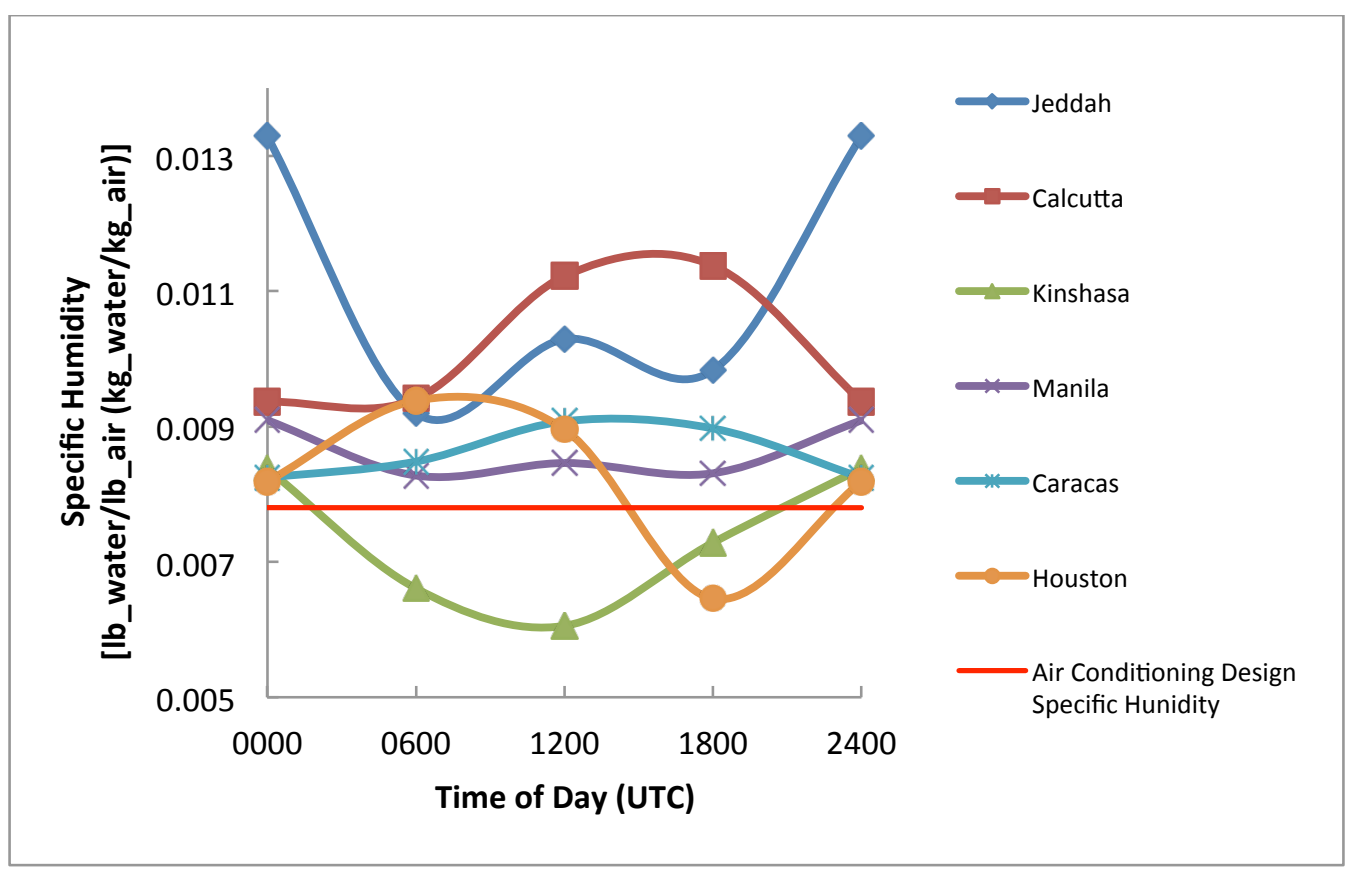

Figure 1. Specific humidity for 6 highly populated cities at 6 -hour intervals on the fall equinox of 2010 (September 23rd).

\section{Global specific humidity analysis}

In order to evaluate global humidity conditions and identify regions with strong condensate collection potential, the specific humidity data from the ERA-INT model was averaged at each grid point over the eleven-year period using an in-house MATLAB script. Collection potential is defined here as the difference between the ambient specific humidity and that of the conditioned air. Assuming the design conditions of $72^{\circ} \mathrm{F}\left(22.2^{\circ} \mathrm{C}\right)$ with $50 \%$ relative humidity for the conditioned air; we have a desired specific humidity of $0.0078 \mathrm{~kg}$ of water per $\mathrm{kg}$ of air. Thus, for example, if the ambient air at a given location has $0.012 \mathrm{~kg}$ water $/ \mathrm{kg}$ air, the water collection potential can be found by:

$0.012-0.0078=0.0042 \frac{\text { kgwater }}{\text { kgair }}$

As noted previously, if the specific humidity of outside air is less than or equal to design conditions the collection is not possible. Hence, in order to calculate the actual collection potential over the elevenyear period, any negative values of the difference must be neglected. Assuming constant specific humidity over each 6-hour period (resolution of the climate model), the collection potential over the eleven-year period at each location can be obtained by summing all of the positive collection potential values. While it is likely that there is some variation of specific humidity over each time step (6-hour), 
we feel this assumption is adequate for the purpose of this study. The resulting solution was then averaged to represent the annual collection potential. The numbers were converted from $\mathrm{lb}$ water/lb air to gallons of water per year per cubic foot per minute $(\mathrm{cfm})$ of $100 \%$ outdoor airflow. Thus, Figure 2(a) shows an estimated amount of water that can be collected at any given location throughout the world as a function of the flow rate of outside air. The maximum value is found to be about $45 \mathrm{gal} / \mathrm{cfm} / \mathrm{year}$ (380.7 L/L-s ${ }^{-1} /$ year) that occurs near Arboletes, Colombia (east of the Colombian-Panamanian Border). The results indicate a high condensate collection potential nearest to the equator and are influenced largely by prevailing winds, ocean currents, and topography. Jassim et al. (2006) found comparable results using exergy method in optimizing the geometrical parameters of an air conditioning precooling air re-heater dehumidifier. They showed that the specific humidity difference plays a significant role in optimizing an air conditioning system. For ease of communication, Figure 2(a) is shown as a contour plot of predicted annual condensate collection where each contour represents increment of 5 $\mathrm{gal} / \mathrm{cfm} /$ year (42.3 L L-s ${ }^{-1} /$ year) of collectible water. The boundaries between land and water are shown in white.

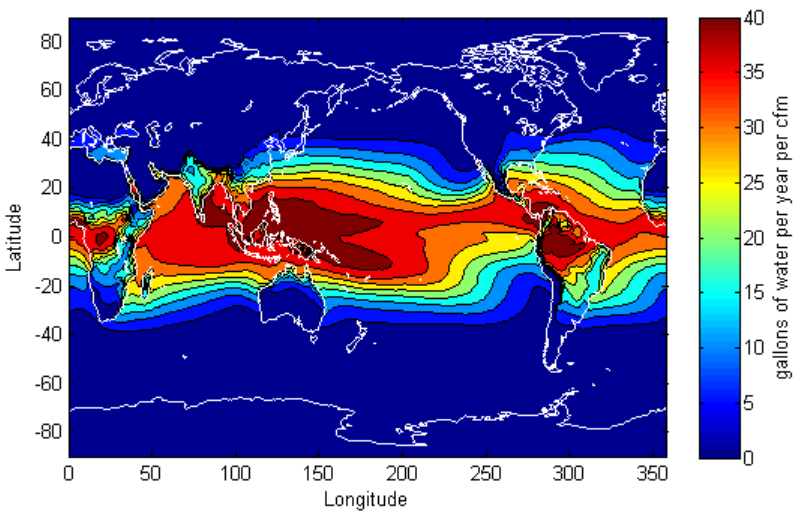

(a)

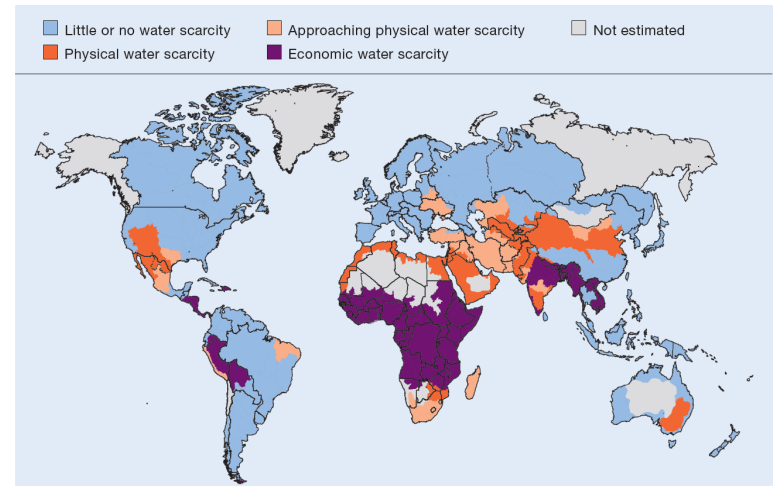

(b)

Figure 2. (a) Estimate of annual collectible water per cfm of $100 \%$ outside airflow rate, (b) Areas of physical and economic water scarcity as reported by the International Water Management Institute (IMWI, 2008).

The results of our calculation can also be applied to estimate the amount of water that can be collected by an air conditioning system at a given location. Error! Reference source not found. shows estimated condensate collection for 31 cities that were selected based on their population and location. Using this information, condensate collection can be predicted for a building in any of these locations based on the flow rate of outside air. For example, a large building at King Abdullah University of Science and Technology (KAUST) campus near Jeddah, Saudi Arabia with 11,000 L/s (23,308 cfm) of 
$100 \%$ outside air flow is predicted to collect 2.82 million Litres (746,000 gallons) per year of condensate water. A building with the same flow rate of air in Singapore would collect 3.82 million Liters (1.01 million gallons) per year. Lawrence et al. predicted annual condensate collection for Houston to be 22.4 $\mathrm{gal} / \mathrm{cfm}\left(189.5 \mathrm{~L} \mathrm{~L}^{-1}\right)$ compared to our prediction of $17.5 \mathrm{gal} / \mathrm{cfm}\left(148.4 \mathrm{~L} / \mathrm{L}-\mathrm{s}^{-1}\right)$. The difference between these two predictions can be attributed to a few differentiating elements of the respective analyses. The estimation made by Lawrence et al. is based on TMY2 hourly data, which represents a typical meteorological year between 1961 and 1990. The analysis carried out in this work is based on a combination of observed weather data and climate modeling at 6-hour time intervals between 2000 and 2010. Thus, the difference may be related to global climate change in the past 50 years, time resolution of the data, or any combination of the two. However, TMY2 or TMY3 data does not exist for areas outside the United States, so the close agreement between these two analyses shows that our findings can be applied to a much larger range of locations. Further, our method can be applied to larger data sets like ERA-40, which contains data from 1957 to 2002 at similar 6-hour intervals.

Table 1. Annual condensate collection potential for various cities.

\begin{tabular}{|c|c|c|c|c|}
\hline City & Country & Population & \multicolumn{2}{|c|}{ Annual Collection Potential } \\
\hline Manila & Philippines & $16,300,000$ & 41.19661766 & 348.5233854 \\
\hline Singapore & Singapore & $3,587,000$ & 41.06872004 & 347.4413715 \\
\hline Lagos & Nigeria & $13,488,000$ & 40.7794785 & 344.9943881 \\
\hline Jakarta & Indonesia & $18,900,000$ & 39.67008336 & 335.6089052 \\
\hline Abidjan & Cote d'Ivoire & $3,359,000$ & 38.38948646 & 324.7750554 \\
\hline Bogota & Colombia & $6,834,000$ & 38.08218023 & 322.1752447 \\
\hline Caracas & Venezuela & $3,153,000$ & 36.70174118 & 310.4967304 \\
\hline Ho Chi Minh & Vietnam & $6,424,519$ & 36.66868091 & 310.2170405 \\
\hline Kinshasa & DRC & $5,068,000$ & 36.33923473 & 307.4299258 \\
\hline Bandung & Indonesia & $3,420,000$ & 35.89923885 & 303.7075607 \\
\hline Bangkok & Thailand & $7,221,000$ & 35.77206263 & 302.6316498 \\
\hline Santo Domingo & Dominican Republic & $3,601,000$ & 35.69768794 & 302.00244 \\
\hline Recife & Brazil & $3,307,000$ & 33.95226226 & 287.2361387 \\
\hline Yangon/Rangoon & Myanmar (Burma) & $4,458,000$ & 33.91133853 & 286.889924 \\
\hline Dhaka & Bangladesh & $10,979,000$ & 31.8300348 & 269.2820944 \\
\hline Calcutta & India & $15,100,000$ & 30.92376255 & 261.6150312 \\
\hline Chennai & India & $6,639,000$ & 30.4710498 & 257.7850813 \\
\hline Jeddah & Saudi Arabia & $3,200,000$ & 30.33979205 & 256.6746407 \\
\hline Salvador & Brazil & $3,180,000$ & 30.12258975 & 254.8371092 \\
\hline Dubai & United Arab Emirates & $1,204,000$ & 28.99572952 & 245.3038718 \\
\hline Hong Kong & China & $6,097,000$ & 25.71944883 & 217.5865371 \\
\hline Mumbai & India & $19,200,000$ & 24.47753005 & 207.0799042 \\
\hline Hanoi & Vietnam & $3,678,000$ & 24.45090181 & 206.8546293 \\
\hline Sao Paulo & Brazil & $18,850,000$ & 22.91499698 & 193.8608744 \\
\hline Bangalore & India & $5,544,000$ & 22.74736192 & 192.4426819 \\
\hline Delhi & India & $18,680,000$ & 21.424562 & 181.2517945 \\
\hline Rio de Janeiro & Brazil & $10,556,000$ & 21.31608074 & 180.3340431 \\
\hline Guangzhou & China & $5,162,000$ & 20.71306081 & 175.2324944 \\
\hline Karachi & Pakistan & $11,800,000$ & 19.65185026 & 166.2546532 \\
\hline Houston & United States & $4,750,000$ & 17.54480611 & 148.4290597 \\
\hline Dammam & Saudi Arabia & 903,312 & 7.052649079 & 59.66541121 \\
\hline
\end{tabular}




\section{Regional analysis}

Analysis from previous section (Figure 2(a)) and Table 1 showed that there are quite a few regions in the world that have high potential for condensate collection. However, some of these regions also receive large amounts of rain each year and, therefore, condensate collection technology may have a limited impact as a source of potable water. On the other hand, a number of these regions are experiencing some form of water scarcity as shown in Figure 2(b). Four regions are identified here that have physical or economic water scarcity and simultaneously possess high potential for collecting condensate water. These are: Arabian Peninsula, West Africa, Southeast Asia, and Central \& South America. It is noteworthy that widespread use of air conditioning is needed in order for water collection potential to realize its full impact. Data for air conditioning use can be obtained with some difficulty for a number of countries throughout the world, particularly those with stronger economies. However, such data is not readily available for developing and under-developed countries. McNeil and Letschert (2007) have shown that air conditioning availability can be estimated with reasonable accuracy using Purchase Power Parity (PPP) adjusted Gross Domestic Product per household per month (GDP/hh/Mo). The potential impact of condensate collection on each of the four regions is discussed below.

The area around the Arabian Peninsula including the coasts of the Red Sea, the Persian Gulf and the Gulf of Oman shows remarkable collection potential. Saudi Arabia, Yemen, Oman, Qatar, Bahrain, the United Arab Emirates, Kuwait, Iraq, Iran, Egypt, Eritrea, Djibouti, and Somalia all have borders on these bodies of water and have annual collection rates of up to 41 gallons/cfm/year (347 L/ L-s $\mathrm{s}^{-1} /$ year). As shown in Figure 3, the region has a few spots of very high humidity near the coast; however, humidity further inland plummets to near zero. Water desalination was first implemented to meet physical water scarcity in Kuwait. Desalination, along with unsustainable ground water use, comprises virtually the entire water supply throughout much of the region (Abderrahman, 2010). A rapidly growing population coupled with immigration into oil and gas producing countries is predicted to further compound water supply issues in the region. There is a strong economic disparity in the region between oil-rich countries like Kuwait, Qatar, Saudi Arabia, or the United Arab Emirates and relatively poor countries like Yemen and Somalia (International Monetary Fund, 2010). For those who can afford it, air conditioning is essential in the extreme heat of the Arabian Peninsula. As the success of the condensate collection system at Bahrain Airport Services indicates, this technology has a proven record of success in the region and is primed for increased implementation. 


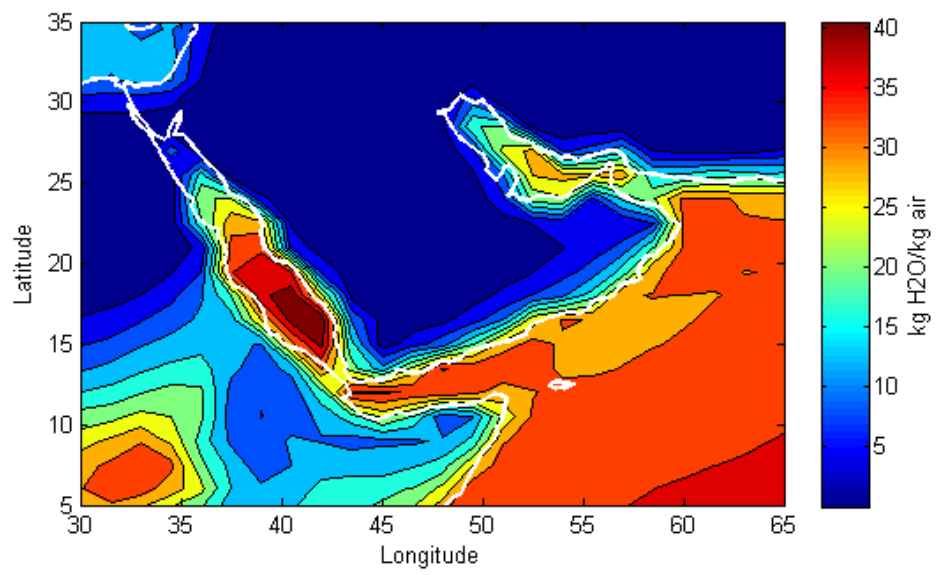

Figure 3. Predicted annual condensate collection for the Arabian Peninsula.

High specific humidity throughout the region stretching from Gambia to the Democratic Republic of the Congo and inland into parts of South Sudan, Ethiopia and Uganda combined with economic water shortages make West Africa another ideal area for condensate collection. However, the region is also markedly poor. While several countries have benefitted from the export of offshore petroleum resources, this wealth is not well distributed and the use of air conditioning systems is relatively limited.

Southeast Asia stretching from American Samoa to the southern coast of Pakistan, and from Bhutan to northern Australia has very high humidity across the region, but physical and economic water scarcities do not exist at every point. India, Pakistan, Nepal, Bangladesh, Bhutan, Myanmar, Laos, Vietnam, and Cambodia are all identified as experiencing an economic or physical water scarcity. With the substantial recent and projected population growth in the region, these water problems are likely to become more exacerbated over time. Several countries, like India, in the region have also experienced tremendous economic growth in recent years, which is expected to continue for the foreseeable future (International Monetary Fund, 2010). As a result of this growth, prime conditions exist to implement condensate collection technology with new installations of air conditioning as compared to the relatively complex process of retrofitting existing infrastructure for condensate collection.

Central and South America is another region where condensate collection can have significant benefits. Areas within this region experiencing water shortages include western Brazil, some Caribbean islands like the Dominican Republic/Haiti, Central America, and parts of Peru, Ecuador and Bolivia. As a region, Latin America has a higher per capita income than Asia or Sub-Saharan Africa, but the availability of air conditioning is still low for several countries in the region (McNeil and Letschert, 2007). 


\section{Water quality testing and applications}

Previous cases of condensate capture have used collected water for sewage, water closet, toilette, and irrigation applications (Guz, 2005; Lawrence et al., 2010); however, there is some potential to use collected water for human consumption and other valuable applications where lower conductivity is required. While water of virtually any content can be treated in order to attain high quality, it can be extremely time and cost-intensive to do so. Hence, a source of water with low conductivity can lead to significant cost savings.

Water quality tests were performed on ten samples from different air conditioning systems throughout Saudi Arabia. The condensate water samples were collected from different air conditioning types (window, split, and central units) installed in regions having varying climate conditions. Table 2 shows the results of these tests with the United States Environmental Protection Agency (EPA) recommended values for each included as a reference. The large central air conditioning unit (CAC) at KAUST is newly installed and professionally maintained. Jeddah is located along the Red Sea coastline whereas Makkah and Riyadh are located in the Arabian Desert with dry climate and frequent sand/dust storms.

Water quality results show that condensate water collected from different locations and air conditioning types is of very high quality with conductivities reaching as low as $18 \mu \mathrm{S} / \mathrm{cm}$ and turbidities as low as 0.041 NTU observed for KAUST central air conditioning unit. All obtained results are under the EPA recommended values. However, it is noticeable that water collected from sites located near the sea, i.e. Jeddah, contains higher salinities reaching $214 \mu \mathrm{S} / \mathrm{cm}$ (approx. $111 \mathrm{mg} / \mathrm{L}$ ), mostly sodium chloride $(51 \mathrm{mg} / \mathrm{L})$, but the quality of this water is still in compliance with WHO standards $(500 \mathrm{mg} / \mathrm{L})$. This could be explained by the fact that this specific air conditioning unit was located very near the sea. For the same location, the salinity of water is higher in window AC than split $\mathrm{AC}$ and it is smallest for the central unit. The turbidity is also higher in window units especially in areas that receive frequent sand/dust storms. The reason is that the window units are more open to the environment (condenser and evaporator are both installed in the same box) compared with split and central systems. We also collected samples from the same unit (KAUST CAC) to study the effect of seasonal changes on water quality. The $\mathrm{pH}$ dropped significantly from May to November while the conductivity and turbidity remained very low. 
Table 2. Results of water quality analysis for different locations in Saudi Arabia.

\begin{tabular}{|c|c|c|c|}
\hline AC Type/Location & $\mathrm{pH}$ & Conductivity $[\mu \mathrm{S} / \mathrm{cm}]$ & Turbidity [NTU] \\
\hline CAC, KAUST (Nov. 2011) & 4.37 & 18 & 0.15 \\
\hline CAC, KAUST (Jun. 2011) & 6.09 & 27 & 0.041 \\
\hline CAC, KAUST (Jun. 2011) & 6.87 & $\mathrm{~N} / \mathrm{A}$ & N/A \\
\hline Window AC, Jeddah & 5.93 & 214 & 5.55 \\
\hline Split AC, Jeddah & 7.35 & 30.3 & 1.62 \\
\hline Window AC, Makkah & 6.77 & 32.5 & 2.47 \\
\hline Split AC, Makkah & 3.05 & 73.4 & 1.63 \\
\hline Window AC, Riyadh & 3.63 & 95.6 & 7.89 \\
\hline Split AC 1, Riyadh & 7.45 & 32.6 & 3.04 \\
\hline Split AC 2, Riyadh & 5.5 & 50.7 & 0.89 \\
\hline $\begin{array}{l}\text { EPA Recommended Value } \\
\text { for potable water }\end{array}$ & $7.0-8.0$ & $<100 \mu \mathrm{S} / \mathrm{cm}$ & $<5 \mathrm{NTU}$ \\
\hline
\end{tabular}

CAC: Central air-conditioning.

The condensate water quality is very close to distillate water quality which ranges between 5 and 50 mg/L (Gacem et al., 2012). With very low-cost polishing treatment such as ion exchange resins (van Deventer, 2011), electrodialysis or electrochemical processes (Drouiche et al., 2009; Xu et al., 2008), the collected water can reach pure water quality and could be used for specific applications in a number of industries such as electronics manufacturing, boilers for steam production, medical/pharmaceutical and laboratory applications as well as for agriculture. The collected water can also be used for municipality purposes by connecting the condensate with water network or blending it with ground water, if available, and treating it (post-treatment) to meet the local water standards (Gacem et al., 2012). It could also be stored in aquifers and recovered when needed using Aquifer Storage and Recovery (ASR) or Aquifer Recharge and Recovery (ARR) systems as proposed by Ghaffour et al. (2012) and Missimer et al. (2011) for desalinated seawater and treated wastewater storage, respectively. With these systems the injected water will be naturally filtered through the soil before being mixed with the native water.

While condensate collection is much smaller in scale than methods like desalination, it requires much less initial investment. It has been shown by a number of studies that the technology can economically reduce the burden of strained water supplies even when used for irrigation and toilettes. Further, the potential application of collected water to higher water quality, and thus higher value, needs increases the economic attractiveness as a means of small-scale water supply. 


\section{Conclusions}

The ERA-INT climate model was used to predict condensate collection potential throughout the world, with a maximum value of about $45 \mathrm{gal} / \mathrm{cfm} / \mathrm{year}$. The analysis indicates that condensate collection technology has numerous potential benefits for high humidity regions as a retrofit or as a component of new system designs. However, large scale benefits can only be realized once a large number of collection systems are installed. Four world regions (Arabian Peninsula, West Africa, Southeast Asia, and Central \& South America) that are undergoing some sort of water scarcity are discussed further to illustrate the potential impact of the proposed condensate collection technology. Detailed water quality tests were conducted to suggest possible uses of the collected water. The high quality of the condensate water shows that the implementation of condensate collection strategy can lead to substantial, albeit seasonal, cost savings and environmental impact reductions in a number of industrial applications where highly pure water is needed. Relatively simple post-treatment methods can make the collected water fit for drinking.

\section{Glossary}

Potable Water - water that is drinkable according to WHO and local standards.

Clean Water - water that can be used in clean industry such as electronics or boilers but may or may not be suitable for drinking water, much like distilled water.

\section{Acknowledgments}

We are thankful to Professor Georgiy Stenchikov for his help with the climate model. We would also like to acknowledge Dr. Faisal Wali, Lab Manager of KAUST Water Desalination and Reuse Center (WDRC), for his help with water quality tests. 


\section{References}

Guz K (2005) Condensate Water Recovery. ASHRAE Journal 47(6), 54-56

Lawrence T, Perry J (2010) Capturing Condensate from High Performance Buildings. ASHRAE Journal 52(1) 56-60

Lawrence T, Perry J, Dempsey, P (2010) Capturing Condensate By Retrofitting AHUs. ASHRAE Journal 52(1), 48-54

Lawrence T, Perry J, Dempsey P (2010) Predicting Condensate Collection from HVAC Air Handling Units ASHRAE Transactions 116(2), 3-15

McNeil M, Letschert V (2007) Future Air Conditioning Energy Consumption in Developing Countries and what can be done about it: The Potential of Efficiency in the Residential Sector. ECEEE Summer Study, Côte d'Azur, France

Missimer TM., Drewes J.E., Maliva R.G., Amy G. (2012). Aquifer Recharge and Recovery:

Groundwater Recharge Systems for Treatment, Storage, and Water Reclamation. Ground Water 49, 771

Painter FL (2009) Condensate Harvesting from Large Dedicated Outside Air-Handling Units with Heat Recovery. ASHRAE Transactions 115(2), 573-580

Quteishat K (2009) Desalination and water affordability. SITeau International Conference, Casablanca, Morocco

IMWI (2008). Water for Food Water for Life: A Comprehensive Assessment of Water Management in Agriculture Development 51(1), 161-162

International Monetary Fund (2010) World Economic Outlook

Jagerskog A (2003) Why states cooperate over shared water: The water negotiations in the Jordan River Basin. Sweden: Department of Water and Environmental Studies, Linköping University

Jassim RK, Khir T, Ghaffour N (2006) Thermoeconomic optimization of the geometry of an air conditioning precooling air reheater dehumidifier. Int. J. Energy Res 30(4), 237-258

Reddy KV, Ghaffour N (2007) Overview of the cost of desalinated water and costing methodologies. Desalination 205(1-3), 340-353

Tropp H, Jagerskog A (2006) Water scarcity challenges in the Middle East and North Africa (MENA). Human Development Report Office (HDRO), United Nations Development Program (UNDP)

Deventer J (2011) Selected Ion exchange applications in the hydrometallurgical industry. Solvent Extraction and Ion Exchange 29(5-6), 695-718

Wilcox S, Marion W (2007) Users manual for TMY3 data sets. National Renewable Energy Laboratory, Golden, Colorado, USA 
World Health Organization (WHO) (2008) The World Health Report

Xu P, Drewers JE, Heil D, Wang D (2008) Treatment of brackish produced water using carbon aerogelbased capacitive deionization technology. Water Research 42, 2605-2617

Abderrahman WA (2010) Sustainable Water and Food Security and Wastewater Reuse in Saudi Arabia, keynote presentation delivered at a special session on Management Solutions for Water Resources in Saudi Water \& Power Forum (SWPF), 5th Oct' 2010, Jeddah, KSA

Allan R (2002) Coping with water scarcity: The governance challenge. Policy paper of the Institute on Global Conflict and Cooperation, UC Berkeley

Brooks DB, Mehmet O (2000) Modern and Traditional Irrigation Technologies in the Eastern Mediterranean. IDRC Report

Chartrand S (2001) Patents: Draw water from air, measure how much water you drink and be kind to the fish you catch. New York Times, (July 02, 2001)

Dee DP, Uppala SM, Simmons AJ, Berrisford P, Poli P, Kobayashi S, Vitart F (2011) The ERA-Interim reanalysis: configuration and performance of the data assimilation system. Quarterly Journal of the Royal Meteorological Society 137(656), 553-597

Drouiche N, Lounici H, Drouiche M, Mameri N, Ghaffour N (2009) Removal of fluoride from photovoltaic wastewater by electrocoagulation and products characteristics. Desalination \& Water Treatment 7, 236-241

Drouiche N, Ghaffour N, Naceur MW, Mahmoudi H, Ouslimane T (2011) Reasons for the fast growing seawater desalination capacity in Algeria. Water Resources Management 25(11), 2743-2754

El-Kharraz J, El-Sadek A, Ghaffour N, Mino E (2012) Water scarcity and drought in WANA countries. Procedia Engineering, 33, 14-29

Gacem Y, Taleb S, Ramdani A, Senadjki S, Ghaffour N (2012) Physical and chemical assessment of MSF distillate and SWRO product for drinking purpose. Desalination, 290, 107-114

Ghaffour N, Missimer T, Amy GL (2012) Combined desalination, water reuse and aquifer storage and recovery to meet water supply demands in the GCC/MENA region. Desalination \& Water Treatment, in press (http://dx.doi.org/10.1080/19443994.2012.700034) 


\section{List of tables}

Table 3. Annual condensate collection potential for various cities.

Table 4. Results of water quality analysis for different locations in Saudi Arabia.

\section{List of figures}

Figure 4. Specific humidity for 6 highly populated cities at 6-hour intervals on the fall equinox of 2010 (September 23rd).

Figure 5. (a) Estimate of annual collectible water per cfm of 100\% outside airflow rate, (b) Areas of physical and economic water scarcity as reported by the International Water Management Institute (IMWI, 2008).

Figure 6. Predicted annual condensate collection for the Arabian Peninsula. 